\section{Interface medicine}

Many people, including myself, have written about the need for transformative change in the delivery of urgent care across the primary/secondary interface. We have argued the case that 'something must be done', that there should be a 'paradigm shift', and made other fine-sounding statements. Professor Lasserson, on the other hand, has gone further by defining what must be done and in which way the paradigm must shift. His article was like a breath of fresh air to me.

We now need to look at next steps. The necessary research that he points to requires the setting up of pilot projects: clinical, technological, and educational. There is no time to lose.

Daniel J Albert,

GP and Urgent Care Doctor, Cumbria

Health on Call, Kendal.

E-mail: daniel.albertanhs.net

\section{REFERENCE}

1. Lasserson D. Interface medicine: a new generalism for the NHS. Br J Gen Pract 2017; DOI: https://doi.org/10.3399/bjgp17X693173.

DOI: https://doi.org/10.3399/bjgp17X693581

\section{Pharmacists are not physician assistants}

I read this editorial, which questions whether pharmacists can reduce GP workload. ${ }^{1}$ | find this question very peculiar, because I do not believe that is the main reason why a pharmacist is needed. I wonder whether this is another example on how the role of pharmacists is misunderstood??

I would like to help GPs to have a realistic expectation of having pharmacists in their practice. It is true that pharmacists can facilitate communication with the dispensary pharmacy, and help chronic medication management and medication reconciliation, ${ }^{3}$ all of which minimise interruptions in GP workflow. However, it does not always equate to reduced workload. Usually after a medication review, a responsible pharmacist would identify some drug-therapy problems, and share the monitoring plan with the team Some of these problems may require doctors inputs, which can arguably create more work.

lam disappointed ifGPs' main expectation is to have pharmacists reducing their workload. This sort of thinking would limit pharmacists input in patient care for the sake of saving time and reducing work. During our busy work days, I have seen some of my medical colleagues feeling annoyed by pharmacists interruptions. I would like to gently suggest to these doctors to have a more patientcentred approach in their practice. Similar to many healthcare professionals, pharmacists main duty is to improve patients' quality of care. Their presence supplements the 10-minute GP consultations, which do not always resolve all issues. ${ }^{4}$ It allows drugrelated issues to be delegated to a qualified professional and helps management plans to be followed. If our main goal is only to reduce workload, hiring an assistant may be a better economical option.

To conclude, I would like to borrow a quote from Steve Jobs: 'It doesn't make sense to hire smart people and tell them what to do; we hire smart people so they can tell us what to do.

Eugene YH Yeung,

Doctor, Royal Lancaster Infirmary,

Lancaster.

E-mail: eugeneyhdagmail.com

\section{Competing interests}

Eugene YH Yeung has received salaries from working as a medical doctor and pharmacist, but neither has paid him to write this letter.

\section{REFERENCES}

1. Avery AJ. Pharmacists working in general practice: can they help tackle the current workload crisis? Br J Gen Pract 2017; DOI: https://doi.org/10.3399/ bjgp17X692201.

2. Yeung EYH. Explaining the role of pharmacists in multidisciplinary care. [Letter]. Br J Gen Pract 2017; DOI: https://doi.org/10.3399/bjgp17X692753.

3. Yeung EY. Are we legitimately stopping medications? Use of pharmacist and junior doctor teaching to improve medication reconciliation. [Letter]. Br J Gen Pract 2016. http://bjgp. org/content/are-we-legitimately-stoppingmedications-use-pharmacist-and-junior-doctorteaching-improve laccessed 8 Nov 2017).

4. McCartney M. Margaret McCartney: Why GPs are always running late. BMJ 2017; 358: j3955.

DOI: https://doi.org/10.3399/bjgp17X693593

\section{Patient use of blood pressure self- screening facilities in general practice waiting rooms}

I am grateful to Professor Smith who, in his response to Tompson et al's article on the use of blood pressure selfscreening in general practice, ${ }^{1}$ raises an interesting target population for such a scheme..$^{2}$ Although I agree that the only reason a young, healthy woman may see a health professional is to request a repeat prescription for the combined oral contraceptive pill, it is precisely because of this that I would argue that it is imperative to keep such appointments. Currently, the NHS offers free chlamydia screening tests for under-25s; the reason, of course, is that this age group is at the highest risk of acquiring this sexually-transmitted infection. Chlamydia is asymptomatic in approximately $80 \%$ of cases, yet has devastating health consequences such as pelvic inflammatory disease, ectopic pregnancy, and tubal factor infertility. So, how can we afford to lose this guaranteed contact with the medical profession in light of our reliance on opportunistic testing for this population?

Christine M Shi,

Clinical Medical Student, University of Oxford, Oxford.

E-mail: christine.shilagtc.ox.ac.uk

\section{REFERENCES}

1. Tompson AC, Grant S, Greenfield SM, et al. Patient use of blood pressure self-screening facilities in general practice waiting rooms: a qualitative study in the UK Br J Gen Pract 2017; DOI: https://doi. org/10.3399/bjgp17X690881.

2. Smith C. Patient use of blood pressure selfscreening facilities in general practice waiting rooms: a qualitative study in the UK. [Letter]. $\mathrm{Br}$ $J$ Gen Pract 2017. http://bjgp.org/content/67/660/ e467/tab-e-letters\#patient-use-of-bloodpressure-self-screening-facilities-in-generalpractice-waiting-rooms-a-qualitative-study-in-theuk laccessed 8 Nov 2017). 